\title{
Correlation Analysis between the Ratios of Second Fingers To Fourth Fingers and Athletic Performance in Primary School Students
}

\author{
Fang-Hui LI, \\ Department of Sports, \\ Pingxiang College, Pingxiang, \\ Jiangxi, China, 337055
}

\author{
Yong-Tian HUANG \\ Department of Sports, \\ Yichun College, Yichun, \\ Jiangxi, China, 336000
}

\begin{abstract}
There might be relationship between the ratio (2D:4D) of the 2nd finger length (2D) and the 4th finger length (4D) and the athletic performance. Method: Taken the athletic performance and measured finger length from pupils were enrolled from the Affiliation Primary School of South China Normal University. Aim: probe into relationship between the athletic performance and 2D:4D in domestic pupils. Result and conclusion: The negative relation between right hand 2D:4D and athletic performance, and lower 2D:4D in boy than girl.
\end{abstract}

\section{Keywords-2D:4D, athletic performance, sex}

The second human finger length (second finger length, 2D) and the length of the fourth finger (fourth finger length, 4D) ratio (digit ratio of $2 \mathrm{D}$ and 4D, 2D: 4D) and exercise capacity correlated. Many studies have shown that 2D: 4D has been established before birth, the mother's uterine concentrations of testosterone and testosterone concentrations of adult negatively correlated Testosterone concentration will affect the development of the right hemisphere visual and spatial ability, thus affecting exercise capacity; 2D: 4D differences in regional and ethnic. There is a substantial research internationally, but the domestic 2D: 4D research and athletic ability is still basically a blank. This study investigated pupils 2D: 4D, explore their differences and sports scores and sex.

\section{RESEARCH CONTENTS AND METHODS.}

\section{A. Study}

382 pupils from the Affiliation Primary School of South China Normal University, are Han Chinese students, exclude those bad pictures and photos see the fold means that there were 8 pupils, total effective capacity of 374 pupils, accounting for $97.9 \%$ efficiency number. Fourth grade total of 119 pupils, fifth grade a total of 141 pupils, sixth grade total of 114 pupils; Its $32.5 \%$ of the total number of valid, respectively, 37\%, 30.5\%.Get for students final examination sports scores through all grades of PE teachers, and sports scores into the sports scores failure (less than 60 minutes), a qualified sports scores (60-74 points), good sports scores (75-89 points), sports scores excellent (90 points or more) of these four grades.

\section{B. Data Taken:}

Student's fingers naturally straight, fingers closer, his hands attached to $3 \mathrm{~mm}$ thick glass, with Kodak 600 digital camera, the other side of the glass photographed the entire palm. After retrieving a photo on your computer using Photoshop amount of arm length, close to the palm fingers from the crease to the top of the finger, measure out the righthand man of 2D and 4D length [1].20 Photos repeated random sampling volume 2 times, twice before and after the data are highly correlated (right $\mathrm{r}=0.99$, left $\mathrm{r}=0.98$ ). Calculated by SPSS 2D: 4D; right hand 2D: 4D, left hand 2D: $4 \mathrm{D}$, left and right hand 2D: 4D average.

\section{Statistical Data Analysis :}

Using SPSS 12.0 statistical software package for the measured data for statistical analysis, the data frequency analysis, One-Way ANOVA, Bivariate. Data Results were expressed as mean \pm standard deviation $(X \pm S)$ to represent significance level of $\mathrm{P}<0.05$, very significant level of $\mathrm{P}$ $<0.01$. Since the large sample data, so the entire process of analysis, the data are processed in contingency to calculate more accurate results.

\section{SURVEY RESULTS}

\section{A. Between Gender 2D: 4D Comparison}

TABLE I. BOYS AND GIRLS BETWEEN THE 2D: 4D SINGLE-FACTOR ANALYSIS,

\begin{tabular}{ccc}
\hline & Schoolboy $(\mathrm{X} \pm \mathrm{S})$ & Girls $(\mathrm{X} \pm \mathrm{S})$ \\
\hline $\mathrm{rr}$ & $0.9475 \pm 0.03675$ & $0.9668 \pm 0.03806 \#$ \\
$\mathrm{rl}$ & $0.9546 \pm 0.04362$ & $0.9754 \pm 0.04779 \S$ \\
$\mathrm{rl}$ & $0.9510 \pm 0.03235$ & $0.9711 \pm 0.03406 \triangle$ \\
\hline
\end{tabular}

Note: rr right hand 2D: 4D, ll left hand 2D: 4D, rl for the left and right hand 2D: 4D average.

From Table 1, boys and girls between 2D: 4D comparison: 2D: 4D analysis and comparison between men and women of the existence of very significant difference $\mathrm{P}$ $<0.01$. Show boys 2D: 4D is significantly less than girls 2D: 4D, a bar graph in Figure 1. 
Boys and girls $\mathrm{rr}, \mathrm{ll}, \mathrm{rl}$ column chart

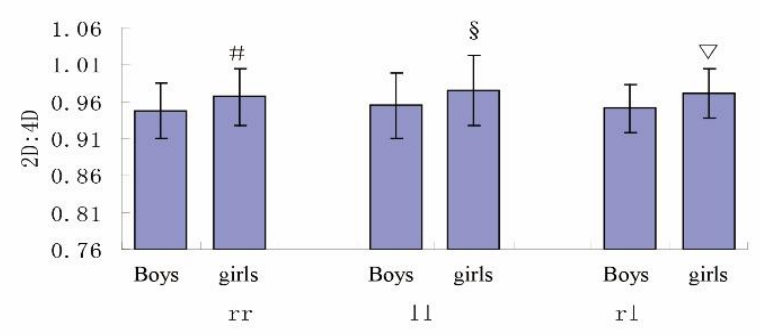

Figure 1. 2D:4D comparison results of Fig. 1 boys and girls students

\#Compare boys rr represents significantly greater $\mathrm{P}<0.01$

$\S$ Boys 11 comparison indicates significantly greater $\mathrm{P}<0.01$

\section{B. 2D:4D Analysis Results between Sports Scores}

TABLE II. THE ANALYSIS OF VARIANCE FOR 2D:4D BETWEEN THE EACH PE GRADES

\begin{tabular}{ll}
\hline & $\mathrm{X} \pm \mathrm{S}$ \\
\hline rr 2D: 4D & $0.9543 \pm 0.03843 \#$ \\
ll 2D: 4D & $0.9696 \pm 0.05906$ \\
rl 2D: 4D & $0.9619 \pm 0.03923$
\end{tabular}

\#representing the each $\mathrm{PE}$ grades rr significantly different $\mathrm{P}<0.05$

The results show (see Table 2) the right of each PE grades in 2D: 4D were significantly different $(\mathrm{P}<0.05)$, while the left hand 2D: 4D and right-hand man 2: 4D does not mean difference. Pass through multiple comparison tests found, Sports Results were excellent right hand 2D: 4D has significantly less than good results, qualified and unqualified persons. The results showed that the right-hand 2D: 4D and sports scores, the lower the better (negative correlation); while the left hand 2D: 4D and right hand 2D: 4D values are of no significant relationship.

The sports grades column chart comparing for $\pi$

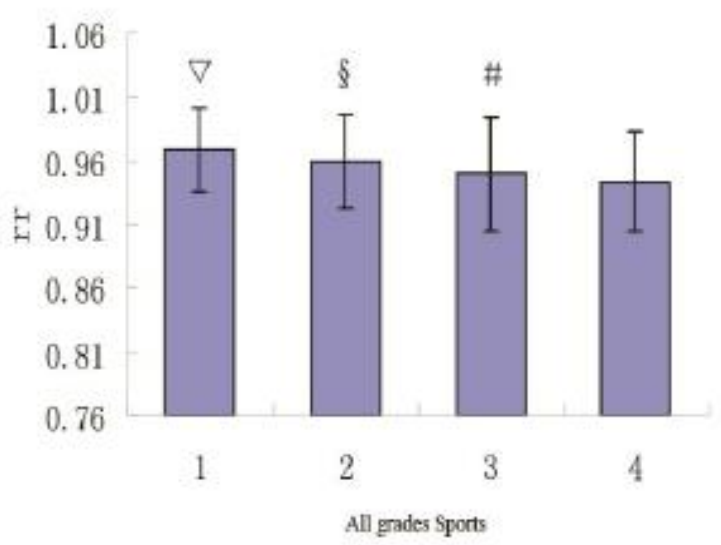

A
The sports grades column chart comparing for 11

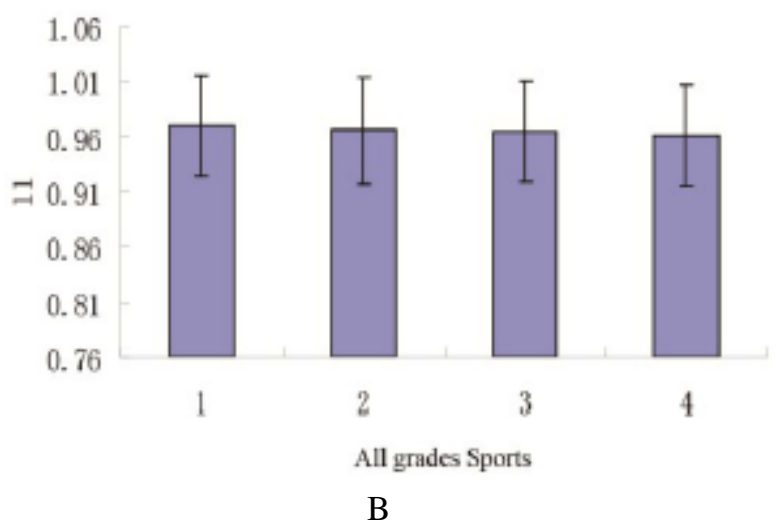

The sports grades column chart comparing for $\mathrm{rl}$

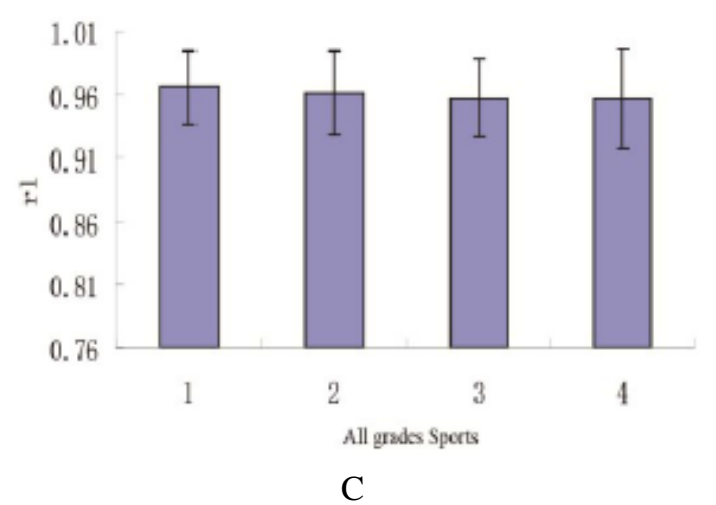

Figure 2.

Abscissa sports level, 1 sports scores substandard (less than 60 points)、 2 qualified sports scores (60-74 points), 3 good sports scores (7589 points), 4 Excellent sports scores (90 or more).rr (right hand 2D: 4D), 11 (left hand 2D: 4D), rl (right hand 2D: 4D Mean)

\section{DISCUSSIONS}

In this study, part of the school to primary school students in South China Normal University as a research object, in a small range of 2D: 4D exploration and research and between men and women and sports scores. Student sports scores are based on the 1990 <National Physical Training Standards Manual $>$ and in February 1992 the State Education Commission issued <Students Sports Qualification Standards Implementation Measures $>$ notice, using percentile evaluation, 60 points or less for the failure (excluding 60 points), 60 points or more qualified, a good 75 points or more, more than 90 points for excellence; Its assessment of the content and the percentage of qualified sports: (1) Physical scores accounted for 60\%; (2) "National Physical Training Standard" test scores accounted for 30\%; (3) actively participate in calisthenics, eye exercises and extra-curricular sports activities (hereinafter referred to as "a two exercise activities") accounted for $10 \%$. In the survey the sports scores failure (less than 60 points) 46 pupils, the total number of $11.5 \%$; qualified sports scores (60-74 points) 95 
pupils, the total number of 25.5\%; good sports scores (75-89 points) 122 pupils, $33 \%$ of the total number; sports scores excellent ( 90 points or more), 111 pupils, $30 \%$ of the total number.

\section{A. 2D:4D Analysis between the Results of Gender}

The survey showed that boys 2D: 4D less than girls. Similar research reports also show that male 2D: 4D than small females [2][3][4][5].We know that 2D: 4D in the womb has been determined, 2D: 4D and testosterone levels and sperm counts were negatively; Positively correlated with the concentration of estradiol ${ }^{[6][7]}$.Another study showed that male testosterone levels and right-hand 2D: 4D inverse relationship ,between women and men of luteinizing hormone (at right), estradiol (at right and left) and prolactin concentration (in right hand) and 2D : 4D into a positive relationship; Also through the gender, age, height and weight control, right-hand 2D: 4D still and luteinizing hormone and estradiol positive correlation relationship ${ }^{[8]}$.The report also explains the above documents present research on male 2D: 4D less than girls.

\section{B. 2D: 4D Analysis and Discussion Among Sports Scores}

The results showed that the right-hand 2D: 4D and sports scores are clearly related; Better performance sports scores, the right-hand 2D: 4D lower, negatively correlated, but left and right hand 2D: 4D and right hand 2D: 4D mean no significant relationship. The current numerous studies also showed that [6] [7] [9] [10] the right-hand 2D: 4D and athletic ability have a significant relationship, while the left hand 2D: 4D and right hand 2D: 4D and the relationship between exercise capacity is not obvious. Some studies youth sports ability and the right hand 2D: 4D negative, but left no differences [9].Voracek al [11] Australia's national fencing by male athletes study also found that the right-hand 2D: 4D and exercise capacity and a significant negative correlation, low 2D: 4D average (right-hand and left-hand insignificant negative correlation) showed sprinting, football, skiing stronger, pointed his right hand 2D: 4D index as the physical ability to judge. The investigation further confirmed that the right-hand 2D: 4D and sports scores showed a significant negative correlation, we hypothesize that the right hand $2 \mathrm{D}$ : 4D and athletic ability were negative phase relationship. Right hand 2D: 4D motion whether as selection indicators also to be studied.

\section{CONCLUSION}

Found that the current international on 2D: 4D and exercise capacity negative correlation, but the 2D: 4D there are regional or ethnic differences. Aiming at South China Normal University Primary School Pupils Part 2D: 4D survey conducted, exploration 2D: 4D relationship with sports scores, fill Dermatoglyphics in 2D: 4D research. Research indicates: Pupils right hand 2D: 4D and sports scores were negatively correlated, boys $2 \mathrm{D}: 4 \mathrm{D}$ is significantly less than girls. We will hand 2D: 4D index as well as a selection of sports into a little research.

\section{ACKNOWLEDGMENT}

Jiangxi Provincial Department of Education Science and Technology Project: GJJ161252

\section{REFERENCES}

[1] Lesxek Pokrywka, Dominik Rachon, et al. The second to fourth digit ratio in elite and Non-elite femal Athletes. American journal of human biology.2005, 17:796-800.

[2] Pokrywka L,Rachon D, Suchecka-Rachon K,Bitel L.The second to fourth digit ratio in elite and non-elite female athletes. Am J Hum Biol. $2005 ; 17(6): 796-800$

[3] Sanders G,Bereczkei T,Csatho A,Manning J.The ratio of the 2nd to 4th finger length predicts spatial ability in men but not women. Cortex. 2005; 41(6):789-95.

[4] Fink B,Neave N,Manning JT.Second to fourth digit ratio, body mass index, waist-to-hip ratio, and waist-to-chest ratio: their relationships in heterosexual men and women. Ann Hum Biol. 2003; 30(6):728-38.

[5] Manning JT, Morris L, Endurance running and digit ratio (2D:4D): Implications for fetal testosterone effects on running speed and vascular health. Am J Hum Biol. 2007 ,19(3):416-21

[6] Manning JT, Taylor RP.Second to fourth digit ratio and male ability in sport: implications for sexual selection in humans. Evol Hum Behav. $2001 ; 22(1): 61-69$

[7] Manning JT.The ratio of 2nd to 4th digit length and performance in skiing. J Sports Med Phys Fitness. 2002; 42(4):446-50.

[8] Manning JT,Scutt D,Wilson J,Lewis-Jones DI. The ratio of 2nd to 4th digit length: a predictor of sperm numbers and concentrations of testosterone, luteinizing hormone and oestrogen. Hum Reprod. $1998 ; 13(11): 3000-4$

[9] Honekopp J,T Manning J,Muller C. Digit ratio (2D:4D) and physical fitness in males and females: Evidence for effects of prenatal androgens on sexually selected traits. Horm Behav. 2006 ;49(4):545-9

[10] Paul SN,Kato BS, Hunkin JL, Vivekanandan S, Spector TD.The big finger: the second to fourth digit ratio is a predictor of sporting ability in women. Br J Sports Med. 2006 Dec; 40(12):981-3. Epub 2006 Sep 28.

[11] Voracek M, Dressler SG.Digit ratio (2D:4D) in twins: heritability estimates and evidence for a masculinized trait expression in women from opposite-sex pairs Psychol Rep. 2007 ;100(1):115-26 